\title{
(6) OPEN ACCESS \\ Recent time trends in incidence, outcome and premorbid treatment of atrial fibrillation-related stroke and other embolic vascular events: a population-based study
}

\author{
Gabriel S C Yiin, Dominic P J Howard, Nicola L M Paul, Linxin Li, Ziyah Mehta, \\ Peter M Rothwell, on behalf of the Oxford Vascular Study
}

- Additional material is

published online only. To view please visit the journal online (http://dx.doi.org/10.1136/ jnnp-2015-311947)

Stroke Prevention Research Unit, Nuffield Department of Clinical Neurosciences, University of Oxford, Oxford, Oxfordshire, UK

\section{Correspondence to}

Professor Peter M Rothwell, Stroke Prevention Research Unit, Nuffield Department of Clinical Neurosciences, Level 6, West Wing, John Radcliffe Hospital, Oxford OX3 9DU, UK:

peter.rothwell@clneuro.ox.ac.uk

Received 5 August 2015 Revised 26 August 2015 Accepted 16 September 2015 Published Online First 20 October 2015

\section{ABSTRACT}

Background Prevalence of atrial fibrillation (AF) is increasing, due partly to the ageing population. The Birmingham Atrial Fibrillation Treatment of the Aged (BAFTA) Trial, published in 2007, provided strong evidence of the effectiveness of warfarin at age $\geq 80$ years, but the impact on incidence of AF-related stroke and peripheral embolic vascular events is uncertain. Methods We studied age-specific incidence and outcome of all AF-related incident strokes and systemic emboli from 2002 to 2012 in the Oxford Vascular Study. Results of 3096 acute cerebral or peripheral vascular events, 748 (24.2\%) were AF-related. Of the 597 disabling/fatal incident ischaemic strokes, 369 occurred at age $\geq 80$ years, of which $124(33.6 \%)$ were in nonanticoagulated patients with known prior AF. There was no reduction in incident AF-related events after 2007 at all ages ( $n=231$ vs 211; adjusted $R R=1.11,0.91$ to $1.36, p=0.29$ ) or at age $\geq 80$ ( 137 vs $135, R R=1.15$, 0.94 to $1.40, p=0.17)$. Scope for improved prevention at older ages was considerable. Among 208 patients with incident AF-related events at age $\geq 80$ and known prior $A F$, only 19 (9.1\%) were anticoagulated. Of the 189 patients not anticoagulated, $166(87.8 \%)$ had no major disability prior to the event and $167(88.4 \%)$ had a high embolism risk score, of whom $139(83.2 \%)$ were also at low risk of complications. Yet, 125/167 (74.9\%) were dead or institutionalised after the event. Potentially preventable embolic events outnumbered warfarinrelated intracerebral haemorrhages by about 15 -fold (280 vs 19), rising to 50 -fold (189 vs 4) at age $\geq 80$ years.

Conclusions We found no reduction in incidence of AF-related vascular events since publication of the BAFTA trial. A third of all disabling/fatal strokes occur in non-anticoagulated patients with known prior AF.

\section{INTRODUCTION}

It is estimated that 1.1 million people in the UK have atrial fibrillation (AF) ${ }^{1}$ with age-specific prevalence increasing from $0.5 \%$ at $50-59$ years of age to $10 \%$ at $\geq 80$ years. $^{2} \mathrm{AF}$ is one of the most common preventable causes of stroke, conferring a fivefold increased risk of stroke and accounting for about 12500 strokes a year in the UK. ${ }^{3}$ AF-related ischaemic strokes also tend to be severe and to incur high mean costs, ${ }^{4}$ and non-cerebral systemic embolism secondary to AF is also a major burden. ${ }^{5}$
Anticoagulation with warfarin is highly effective in primary prevention of AF-related embolic events, ${ }^{67}$ associated with reduced stroke severity, ${ }^{8} 9$ and several new oral anticoagulants have been shown to have equivalent or greater net clinical benefit. ${ }^{10}$ Yet, irrespective of which drugs are used, the overall impact of anticoagulation on AF-related ischaemic events at the population level has probably been small due to widespread undertreatment, ${ }^{11-13}$ particularly in the elderly (see online supplementary table $\mathrm{S} 1 \mathrm{a}-\mathrm{c}$ ). We showed that there has, in fact, been a three-fold increase in AF-related ischaemic stroke at age $\geq 80$ years in Oxfordshire from 1981-1986 to 2002-2012. ${ }^{14}$ However, screening for $\mathrm{AF}$ and prevention of stroke in primary care were incentivised with the introduction in the UK of the Quality and Outcomes Framework (QOF) in 2006 (see online supplementary table S2), and good evidence that warfarin is more effective than aspirin in primary prevention in high-risk elderly patients with $\mathrm{AF}$ was provided in 2007 with the results of the Birmingham Atrial Fibrillation Treatment of the Aged (BAFTA) trial. ${ }^{15}$ What impact these developments had on the incidence of AF-related vascular events in high-risk older people is uncertain. ${ }^{1} \mathrm{We}$, therefore, determined changes in age and sexspecific incidence of AF-related vascular events in Oxfordshire, UK, before and after 2007, including changes in rates of known prior AF and premorbid treatment in relation to age, sex, risk scores and contraindications, premorbid disability and clinical outcome.

\section{METHODS}

Study population

OXVASC is a population-based study of the incidence and outcome of all acute vascular events in a mixed urban/rural population of Oxfordshire, UK. Methods and definitions of events (see online supplementary S3) have been reported previously. ${ }^{16} 17$ Briefly, the study population comprises 92728 individuals registered with nine general practices (about 100 family doctors) that refer patients to the main Oxford Hospitals. Ascertainment of acute vascular events started in 1 April 2002 and is on-going. Case ascertainment uses multiple overlapping methods of hot and cold pursuit (see online supplementary S3) and has been shown to be near 
complete. ${ }^{17}$ For this paper, only incident transient ischaemic attacks (TIAs), strokes and peripheral embolic vascular events (PVEs) ascertained up to 31 March 2012 were included. OXVASC has local research ethics committee approval.

All patients gave informed consent to participate in OXVASC, or assent was gained from a relative. Patients were seen by study physicians as soon as possible after presentation (assessment details in online supplementary S3). ECG and not ambulatory cardiac monitoring was performed routinely at baseline as part of clinical care. Clinical study reports of all strokes were reviewed by the senior study neurologist and reports of all PVEs were reviewed by a vascular surgeon. We obtained additional premorbid baseline clinical characteristics, lipid profile, BP measurements and medications by interviewing patients and relatives, and by review of primary care and hospital records.

Stroke was defined as an event with appropriate symptoms lasting longer than $24 \mathrm{~h} .{ }^{16}$ PVEs included all cases of presumed embolic acute limb ischaemia or acute visceral ischaemia (including aortic, renal, splenic, hepatic and intestinal). AF-related events were defined as those associated with paroxysmal, persistent or permanent $\mathrm{AF}^{18}$ (defined on the basis of an ECG showing either absent $\mathrm{p}$ waves or atrial flutter with an irregular ventricular response) documented before the event, at the time of assessment, or within 1 month after the event. Patients were subdivided according to whether AF had been documented prior to the acute event ('known prior AF'), with confirmation from primary care or hospital records.

In all patients with known prior $\mathrm{AF}$, we used premorbid clinical characteristics to calculate the $\mathrm{CHADS}_{2}$ score $^{19}$ and $\mathrm{CHA}_{2} \mathrm{DS}_{2}$ VASc score ${ }^{20}$ for risk of embolic ischaemic events, and the HAS-BLED score ${ }^{21}$ for the risk of bleeding on anticoagulation. In those patients not on anticoagulation at the time of the event, we reviewed their primary care and hospital records to identify any written explanation as to why anticoagulation was not used and identified any reasons for previous discontinuation. Aetiological subtype of stroke was classified with the TOAST criteria (Trial of Org 10172). ${ }^{22}$

All patients had face-to-face follow-up at 1, 6, 12, 24, 60 and 120 months after the event to assess outcomes. For patients who had moved out of the study area, telephone follow-up was performed. Follow-up was conducted via a carer if the patient was unable to participate, for example, due to dementia. Institutionalisation was defined as living in a nursing home, residential home or community rehabilitation hospital. Major ischaemic stroke was defined as National Institutes of Health (NIH) stroke scale $\geq 5$. Disabling/fatal stroke or PVE were defined as having a modified Rankin scale (mRS) score $>2$ at 6-months follow-up. Premorbid disability was also defined as $m R S>2$, with major disability defined as $m R S>3$ (ie, not independently mobile).

\section{Statistical analysis}

Sex-specific rates (per 1000 population per year) of AF-related incident strokes and PVEs were calculated in 10-year age bands, with CIs estimated assuming a Poisson distribution. We used Poisson regression models to calculate the relative incidence of AF-related ischaemic event between time periods in OXVASC. We used $\chi^{2}$ or Fisher's Exact test to compare categorical variables and Student $t$ test for continuous variables. Binary logistic regression was used to calculate the age-adjusted OR.

We performed statistical analysis and graphical presentation using SPSS software V.20.0, Microsoft Excel 2010 for Windows and SAS software V.9.2.

\section{Role of the funding source}

The sponsor of the study had no role in the study design, data collection, data analysis, data interpretation, or writing of the report. All authors had access to the data and took responsibility for the decision to submit the manuscript.

\section{RESULTS}

Of 3096 acute cerebral or peripheral vascular events in OXVASC during 2002-2012, 748 (24.2\%) were AF-related, including 601 incident events (383 ischaemic stroke, 122 TIA, 71 PVE and 25 intracerebral haemorrhage), of whom 442 $(73.5 \%)$ had documented prior AF. Baseline characteristics are given in table 1 .

Incidence rates of AF-related ischaemic stroke or PVE were similar in men and women, but increased steeply with age, with $272 / 454(59.9 \%$ ) events occurring at $\geq 80$ years (table 2 , online supplementary tables S4-5). Of 1425 patients with incident ischaemic stroke (1248) or PVE (177) in the study population, the proportion with AF-related events increased from $7.8 \%$ at age $<60$ years to $50.7 \%$ at age $\geq 90$ (figure 1). The severity of AF-related cerebral events also increased steeply with age $(\mathrm{p}<00001$; figure 2$)$, the proportion that were disabling or fatal ischaemic strokes reaching $51.4 \%$ by age $\geq 90$ years.

There was no reduction in number of AF-related ischaemic strokes and PVEs between 2007-2012 and 2002-2007 ( $\mathrm{n}=231$ vs 223 ; identical incidence $=0.49 / 1000 /$ year, 95\% CI 0.43 to 0.56 ; age/sex-adjusted RR $1.11,0.91$ to $1.36, \mathrm{p}=0.29)$, with similar results for events at age $\geq 80$ years ( 137 vs $135, R R=1.15$, 0.94 to $1.40, \mathrm{p}=0.17)$ and in paroxysmal AF-related events $(74 /$ 223 vs 67/231, $\mathrm{p}=0.34)$. However, the rates of AF-related vascular events tended to be higher in 2010-2012 than in 2007-2009 (table 3 ) especially at age $\geq 80$ years ( 8.03 vs $5.89 / 1000 /$ year for any AF and 6.30 vs 5.28/1000/year for premorbid AF).

Of the 454 patients with AF-related incident ischaemic stroke and PVE, 436 (96\%) had non-valvular AF, 129 (28.4\%) had

Table 1 Baseline characteristics of patients with AF-related and non-AF-related incident ischaemic stroke

\begin{tabular}{|c|c|c|c|c|}
\hline & $\begin{array}{l}\text { Non-AF } \\
(n=865)\end{array}$ & $\begin{array}{l}A F \\
(n=383)\end{array}$ & $\begin{array}{l}\text { Premorbid } \\
\text { AF }(n=274)\end{array}$ & $\begin{array}{l}\text { Unadjusted } \\
\text { p value* }\end{array}$ \\
\hline Male sex (\%) & $457(52.8)$ & $171(44 \cdot 6)$ & $126(46 \cdot 0)$ & 0.008 \\
\hline Mean age (SD) (years) & $73.0(13.5)$ & $80.0(9.7)$ & $80.4(9.4)$ & $<0.0001$ \\
\hline $\begin{array}{l}\text { Congestive cardiac } \\
\text { failure }\end{array}$ & $55(6.4)$ & $99(25 \cdot 8)$ & $85(31 \cdot 0)$ & $<0.0001$ \\
\hline Hypertension & $530(61.3)$ & $287(74 \cdot 9)$ & $212(77 \cdot 4)$ & $<0.0001$ \\
\hline Diabetes & $124(14.3)$ & $58(15 \cdot 1)$ & $49(17 \cdot 9)$ & 0.71 \\
\hline Previous TIA & $98(11.3)$ & $61(15 \cdot 9)$ & $46(16 \cdot 8)$ & 0.025 \\
\hline Previous MI & $91(10.5)$ & $72(18 \cdot 8)$ & $59(21 \cdot 5)$ & 0.0001 \\
\hline Angina & $136(15.7)$ & $102(26.6)$ & $87(31 \cdot 8)$ & $<0.0001$ \\
\hline Current smoking & $155(17.9)$ & $29(7 \cdot 6)$ & $17(6 \cdot 2)$ & $<0.0001$ \\
\hline Hypercholesterolaemiat & $276(31.9)$ & $118(30 \cdot 8)$ & $88(32 \cdot 1)$ & 0.70 \\
\hline $\begin{array}{l}\text { Peripheral vascular } \\
\text { disease }\end{array}$ & $65(7.5)$ & $56(14 \cdot 6)$ & 40 (14.6) & 0.0001 \\
\hline Valvular heart disease & $60(6.9)$ & $82(21 \cdot 4)$ & $73(26 \cdot 6)$ & $<0.0001$ \\
\hline $\begin{array}{l}\text { Venous } \\
\text { thromboembolism }\end{array}$ & $48(5.5)$ & $27(7.0)$ & $21(7.7)$ & 0.30 \\
\hline Antiplatelet agent(s) & $293(33.9)$ & $202(52 \cdot 7)$ & $167(60.9)$ & $<0.0001$ \\
\hline Lipid lowering agent & $214(24.7)$ & $102(26 \cdot 6)$ & $82(29 \cdot 9)$ & 0.48 \\
\hline Antihypertensive(s) & $484(56.0)$ & $282(73 \cdot 1)$ & $212(77.4)$ & $<0.0001$ \\
\hline Anticoagulant & $9(1.0)$ & $47(12 \cdot 3)$ & $46(16 \cdot 8)$ & $<0.0001$ \\
\hline
\end{tabular}


Table 2 Age-specific rates per 1000 population per year of AF-related incident ischaemic stroke and peripheral embolic vascular event in OXVASC

\begin{tabular}{|c|c|c|c|c|c|c|}
\hline Age (years) & Men & Rate per 1000 per year $(95 \% \mathrm{CI})$ & Women & Rate per 1000 per year $(95 \% \mathrm{CI})$ & Total & Rate per 1000 per year $(95 \% \mathrm{Cl})$ \\
\hline$<60$ & $13 / 38736$ & $0.03(0.02$ to 0.06$)$ & $1 / 35656$ & $0.00(0.00$ to 0.02$)$ & $14 / 74392$ & $0.02(0.01$ to 0.03$)$ \\
\hline $60-69$ & $21 / 4308$ & $0.49(0.30$ to 0.75$)$ & $21 / 4332$ & $0.48(0.30$ to 0.74$)$ & $42 / 8640$ & 0.49 (0.35 to 0.66$)$ \\
\hline 70-79 & $65 / 2848$ & 2.28 (1.76 to 2.91$)$ & $61 / 3187$ & 1.91 (1.46 to 2.46$)$ & $126 / 6035$ & 2.09 (1.74 to 2.49$)$ \\
\hline $80-89$ & $83 / 1207$ & 6.88 (5.48 to 8.53$)$ & $111 / 1914$ & 5.80 (4.77 to 6.98$)$ & $194 / 3121$ & 6.22 (5.37 to 7.16$)$ \\
\hline$\geq 90$ & $16 / 147$ & $10.90(6.23$ to 17.71$)$ & $62 / 393$ & 15.79 (12.11 to 20.24$)$ & $78 / 540$ & 14.46 (11.43 to 18.05$)$ \\
\hline \multirow[t]{2}{*}{ Total } & $198 / 47246$ & $0.42(0.36$ to 0.48$)$ & $256 / 45482$ & $0.56(0.50$ to 0.64$)$ & $454 / 92728$ & $0.49(0.45$ to 0.54$)$ \\
\hline & & & & $\begin{array}{l}\text { Premorbid AF } \\
\text { New AF }\end{array}$ & $\begin{array}{l}336 / 92728 \\
118 / 92728\end{array}$ & $\begin{array}{l}0.36(0.32 \text { to } 0.40) \\
0.13(0.11 \text { to } 0.15)\end{array}$ \\
\hline
\end{tabular}

$A F$, atrial fibrillation.

paroxysmal AF and $325(71.6 \%)$ had permanent AF (see online supplementary tables S6-7). The characteristics of patients with AF-related ischaemic stroke and PVE were broadly similar (see online supplementary table S8a-d). Patients with AF-related incident ischaemic stroke had higher prevalence of vascular risk factors and usage of secondary preventative medications compared to those with non-AF-related stroke (table 1). In addition, AF-related strokes were also less likely to be minor $(\mathrm{NIHSS}<5)$ : NIHSS $\geq 10$ vs $0-4 ; \quad O R=3.18,2.32$ to $4.36, \quad \mathrm{p}<0.0001$. Consequently, of 597 incident ischaemic strokes that were fatal or disabling at 6 months follow-up, 262/597 (43.9\%) were
AF-related (age-adjusted $\mathrm{OR}=2.52,1.87$ to $3.41, \mathrm{p}<0.0001$ ) and $165(27 \cdot 6 \%)$ occurred in non-anticoagulated patients with known prior AF. Of the 369 incident ischaemic strokes at age $\geq 80$ that were fatal or disabling at 6 months, $124(33.6 \%)$ occurred in non-anticoagulated patients with known prior AF. Of those who survived at 6 months, the AF group had higher disability (mRS 3-5) than the non-AF group (49.6\% vs $28.9 \%$; age-adjusted $\mathrm{OR}=1.84,1.34$ to $2.53, \mathrm{p}=0.0002$ ).

Among the 336 patients with incident ischaemic stroke or PVE, and known prior AF (figure 3), only 56 (16.7\%) were anticoagulated (46/274 stroke and 10/62 PVE), with no increase
Figure 1 Proportion of incident ischaemic strokes (left bars) and peripheral embolic vascular events (right bars) related to all atrial fibrillation AF by age for all events (A) and disabling/fatal events (B).
A All events

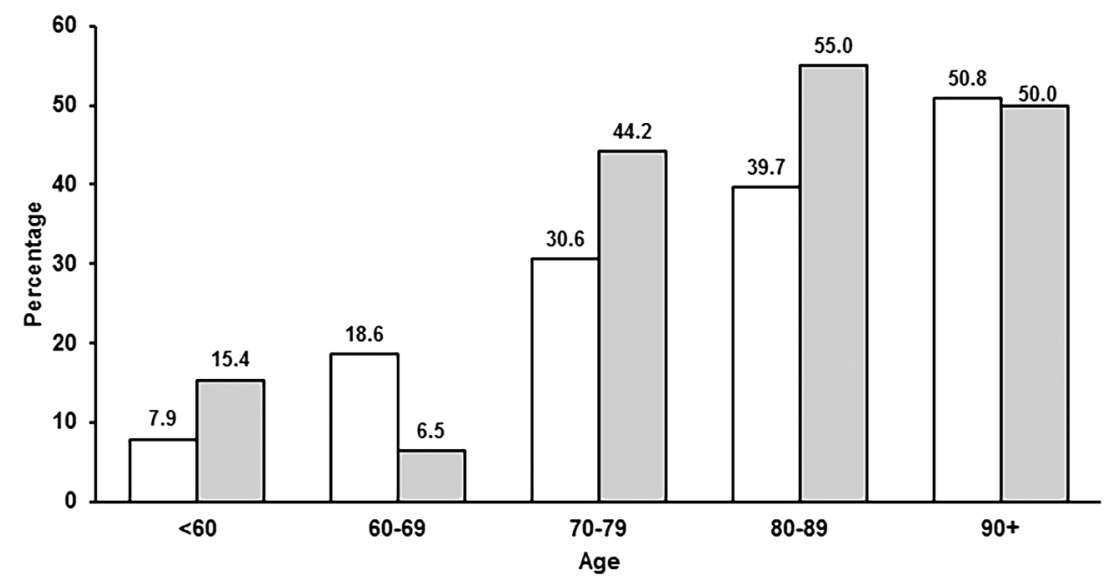

B Disabling/fatal events

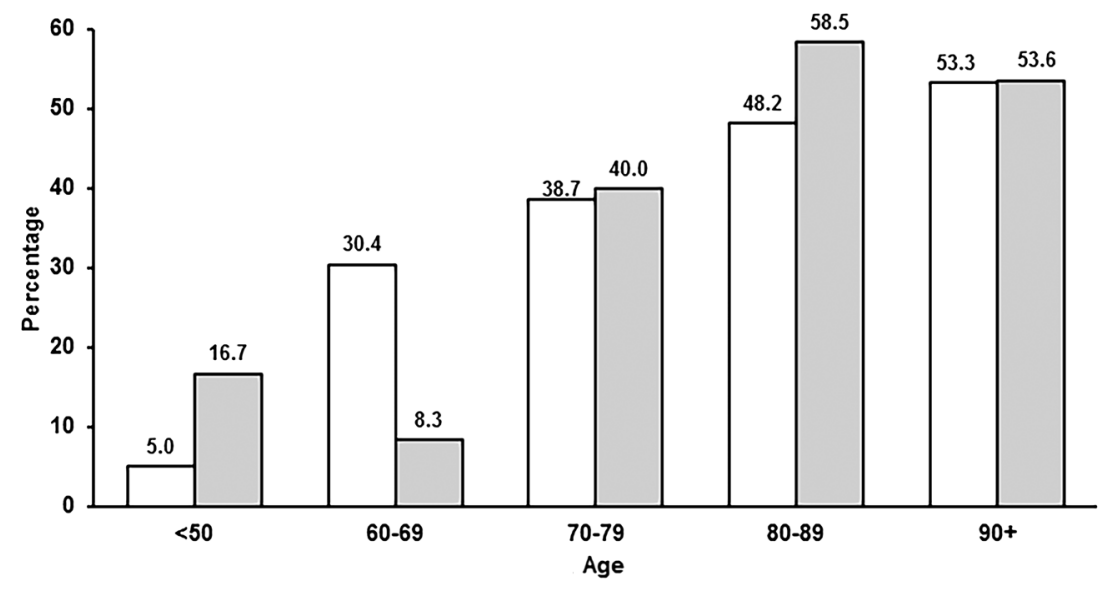


Figure 2 Distribution of incident atrial fibrillation (AF)-related $(A ; n=505)$ and non-AF-related (B; $n=1337$ ) transient ischaemic attacks (TIAs) and ischaemic strokes by age and severity; TIA (white), minor non-disabling ischaemic stroke (grey), major fatal/disabling ischaemic stroke (black).
A AF-related TIA and ischaemic stroke

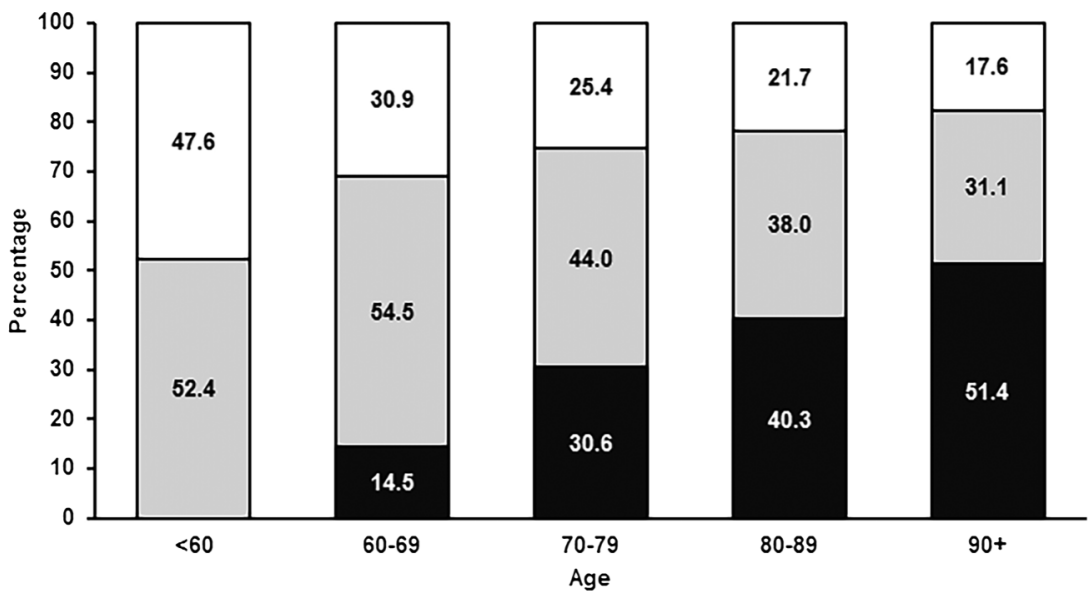

B Other TIA and ischaemic stroke

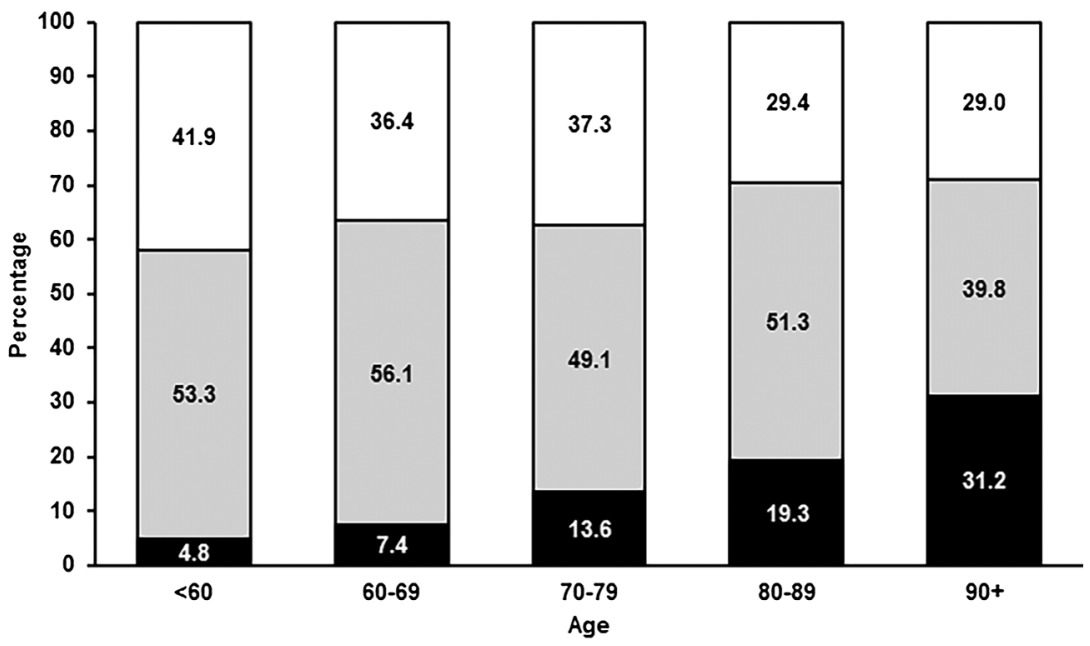

in rates since 2007 (32/178 vs $24 / 158$ in $2002-2007, \mathrm{p}=0.49$ ). Rates were higher $(\mathrm{p}=0.02)$ for persistent/permanent AF (46/233) than for paroxysmal AF (10/103). Of 56 patients who were anticoagulated, the International Normalised Ratio was subtherapeutic in $34(60.7 \%)$.
Of the 280 patients with ischaemic stroke or PVE and not anticoagulated, $217(77 \cdot 5 \%)$ had a $\mathrm{CHADS}_{2}$ score $\geq 2$ (see online supplementary tables S9-12), of whom 51 (23.5\%) had a documented absolute or relative contraindication (see online supplementary table S13) and $181(83.4 \%)$ had a HAS-BLED

Table 3 Age-specific rates of AF-related incident ischaemic stroke and PVE at different time periods

\begin{tabular}{|c|c|c|c|c|c|c|}
\hline \multirow[b]{2}{*}{ Ischaemic stroke or PVE } & \multicolumn{2}{|l|}{ All ages } & \multicolumn{2}{|l|}{ Age $<80$} & \multicolumn{2}{|l|}{ Age $\geq 80$} \\
\hline & Rate/1000/year & Number & Rate/1000/year & Number & Rate/1000/year & Number \\
\hline \multicolumn{7}{|l|}{ Total AF } \\
\hline 2002-2012 & $0.49(0.45-0.54)$ & 454 & $0.20(0.18-0.24)$ & 182 & $7.43(6.57-8.37)$ & 272 \\
\hline $2002-2007$ & $0.49(0.43-0.56)$ & 223 & $0.20(0.16-0.25)$ & 88 & $7.98(6.69-9.45)$ & 135 \\
\hline 2007-2012 & $0.49(0.43-0.56)$ & 231 & $0.21(0.17-0.25)$ & 94 & $6.96(5.84-8.23)$ & 137 \\
\hline $2007-2009.5^{*}$ & $0.42(0.34-0.51)$ & 99 & $0.18(0.13-0.25)$ & 41 & $5.89(4.47-7.62)$ & 58 \\
\hline $2009.5^{*}-2012$ & $0.56(0.47-0.66)$ & 132 & $0.23(0.18-0.31)$ & 53 & $8.03(6.35-10.00)$ & 79 \\
\hline \multicolumn{7}{|l|}{ Premorbid AF } \\
\hline $2002-2012$ & $0.36(0.32-0.40)$ & 336 & $0.14(0.12-0.17)$ & 128 & $5.68(4.94-6.51)$ & 208 \\
\hline $2002-2007$ & $0.35(0.29-0.40)$ & 158 & $0.15(0.11-0.19)$ & 64 & $5.56(4.49-6.80)$ & 94 \\
\hline 2007-2012 & $0.38(0.32-0.44)$ & 178 & $0.14(0.11-0.18)$ & 64 & $5.79(4.78-6.96)$ & 114 \\
\hline 2007-2009.5* & $0.35(0.28-0.44)$ & 83 & $0.14(0.09-0.19)$ & 31 & $5.28(3.95-6.93)$ & 52 \\
\hline $2009.5^{*}-2012$ & $0.40(0.33-0.49)$ & 95 & $0.15(0.10-0.21)$ & 33 & $6.30(4.83-8.08)$ & 62 \\
\hline
\end{tabular}




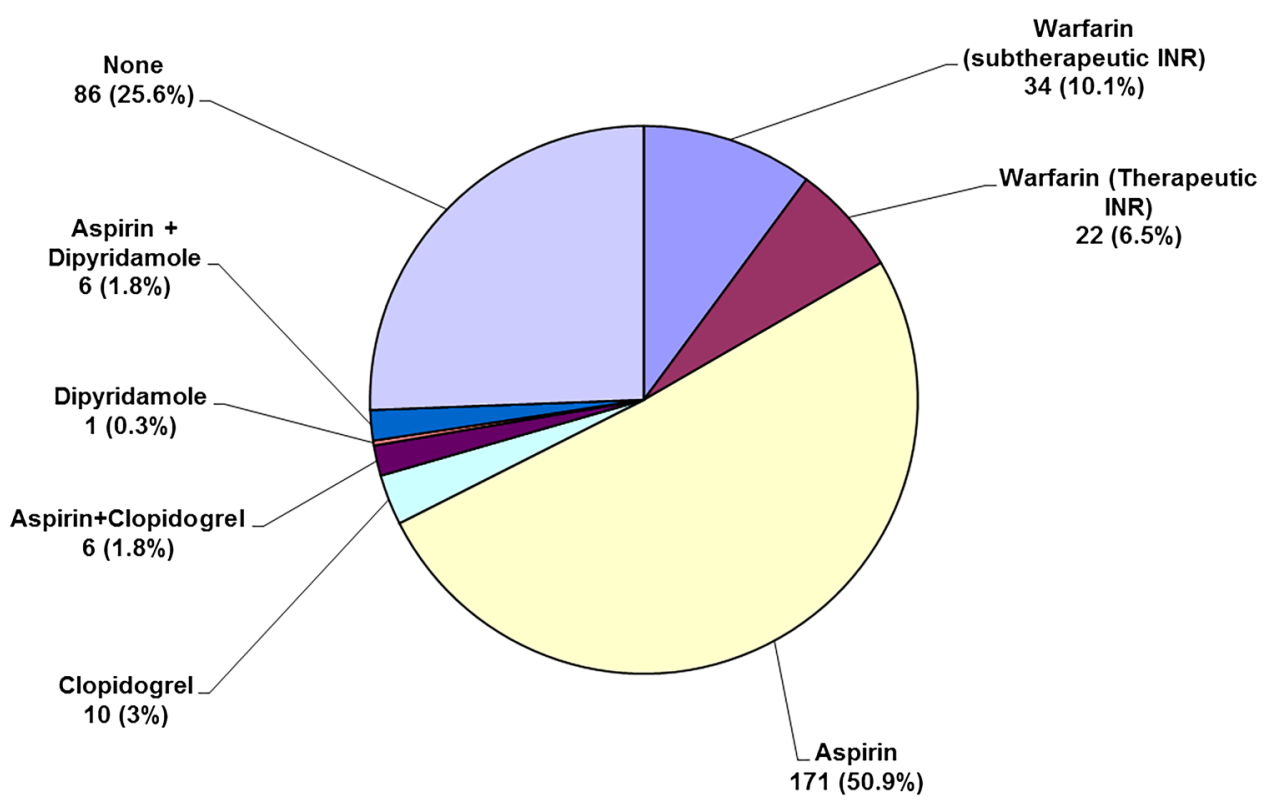

Figure 3 Premorbid antithrombotic therapy in the 336 OXVASC patients with incident atrial fibrillation (AF)-related ischaemic stroke or peripheral embolic vascular event and known prior AF

score $<3$ (see online supplementary table S12). A total of 194 $(57.7 \%)$ were on antiplatelet drugs, but $86(25.6 \%)$ were on no antithrombotic agent (see online supplementary table S9, figure 3). Anticoagulation was associated with reduced severity of stroke (NIHSS: anticoagulated $=5.5 \pm 5.7$; antiplatelet/ none $=8.3 \pm 7.5, \mathrm{p}=0.006)$ and lower proportion of major disabled or fatal ischaemic stroke (16/69 vs $114 / 285, \mathrm{p}=0.01)$.

Rates of premorbid anticoagulation for known prior AF in patients with AF-related ischaemic stroke or PVE were highest at younger ages, falling to $12.9 \%(19 / 147)$ at $80-89$ and $0 \%$ $(0 / 61)$ at $\geq 90$ (see online supplementary table S9). Of the 208 patients aged $\geq 80$ years, 189 (90.9\%) were not anticoagulated but the majority with hypertension (148/168) and hypercholesterolaemia (38/57) were treated. Of these 189, $167(88.4 \%)$ had a premorbid $\mathrm{CHADS}_{2}$ score $\geq 2,139$ (83.2\%) had a HAS-BLED score $<3$ (see online supplementary table S12), and only 10 (5.3\%) had previously had a trial of anticoagulation and had discontinued treatment (see online supplementary table S14). Of the 167 with a $\mathrm{CHADS}_{2}$ score $\geq 2$, only $43(25.7 \%)$ had any documented relative or absolute contraindication (see online supplementary table S13).

Of the 189 patients who were aged $\geq 80$ and not anticoagulated (see online supplementary table S15a, b), $166(87.8 \%)$ had no major disability (ie, were still independently mobilemRS $\leq 3)$ prior to the event and $99(52.4 \%)$ were previously completely independent $(\mathrm{mRS} \leq 2)$. Of these 99 patients, 73 (73.7\%) were dead or disabled 6-months postevent. Of the 167 $(88.4 \%)$ who had an embolism risk score favouring treatment $\left(\mathrm{CHADS}_{2}\right.$ score $\left.\geq 2\right), 125$ (74.9\%) were dead or institutionalised after the event. Indeed, of all disabling or fatal events at age $\geq 80$ in the study population, 230/449 (51.2\%) were AF-related and $181(40.3 \%)$ occurred in patients with known prior AF. Of 136 patients aged $\geq 80$ with known prior $\mathrm{AF}$ and $\mathrm{CHADS}_{2} \geq 2$ who had an incident event resulting in death or institutionalisation at 6-months follow-up, only $11(8 \cdot 1 \%)$ were anticoagulated prior to the event (see online supplementary figure $\mathrm{S} 1 \mathrm{a}-\mathrm{f}$ ). Of 128 patients with an incident intracerebral haemorrhage, 19 had known prior AF, of whom 12 were on warfarin (4 patients aged $\geq 80$ years). The numbers of potentially preventable embolic events outnumbered warfarin-related intracerebral haemorrhages by about 15 -fold ( 280 vs 19$)$ at all ages and 50 -fold (189 vs 4 ) at age $\geq 80$ years.

\section{DISCUSSION}

We have made several observations that have important implications for improving prevention of stroke and other embolic events in patients with AF. First, AF was associated with $32 \%$ of all incident ischaemic strokes and PVEs. Second, one-third of all disabling or fatal ischaemic strokes at age $\geq 80$ occurred in nonanticoagulated patients with known prior AF. Third, only $9 \%$ of patients aged $\geq 80$ years with incident embolic events related to known prior $\mathrm{AF}$ were on premorbid warfarin, despite the majority having a high $\mathrm{CHADS}_{2}$ score and low bleeding risk, and despite the low rate of documented contraindications. Fourth, over half of those patients aged $\geq 80$ who were not on warfarin were previously independent, but nearly three-quarters were dead or disabled 6 months after the event. Finally, we found that there was no improvement in these statistics after 2007, despite the introduction of $\mathrm{AF}$ registers as part of the UK Quality and Outcomes Framework (QOF) in primary care and publication of the results of the BAFTA trial on the safety and effectiveness of anticoagulation in the elderly.

The reasons for the apparent lack of impact of the QOF and the BAFTA trial results are uncertain. Of 454 patients with incident AF-related ischaemic strokes or PVEs, 118 (26\%) patients did not have documented prior AF and were not aware of the diagnosis. However, a significant proportion of this apparently undocumented AF would have been either very recent or potentially have been induced by the ischaemic event itself, and this proportion did not change after 2007. In addition, the QOF rewarded primary care physicians equally for use of anticoagulants or antiplatelet agents in patients with $\mathrm{AF}$ prior to April 2012, despite the very substantial difference in effectiveness and only 6 of 27 available points related to AF in the latest QOF promote anticoagulation (see online supplementary table S2). The 2014 NICE guideline for AF strongly recommends using 
anticoagulation instead of antiplatelet agents, but did not place any particular emphasis on anticoagulation in the elderly. ${ }^{23}$

We found relatively high rates of premorbid antiplatelet drug use in older patients with known prior AF (table 1), reflecting evidence that physicians tended to overestimate the bleeding risks of warfarin and overestimate the benefits of antiplatelet drugs in $\mathrm{AF}^{12}$ Even though the median $\mathrm{CHADS}_{2}$ (2-3), $\mathrm{CHA}_{2} \mathrm{DS}_{2}$ VASc (4-5) and HAS-BLED (1-2) scores were relatively low among OXVASC patients with ischaemic event and known prior AF (probably reflecting the overall low risk for bleeding complications in this population), the embolic risk was consistently higher than the bleeding risk among those at $\geq 80$ years (see online supplementary table $\mathrm{S} 10$ ). The substantial benefit of anticoagulants over antiplatelet drugs in high-risk patients with $\mathrm{AF}$ is maintained at older ages, ${ }^{15}{ }^{24}$ but the anticoagulation rate at age $\geq 80$ in the UK ranges from only $21 \%$ to $46 \%$ (see online supplementary table S1) and studies of physician attitudes and practice show a continuing reticence to prescribe warfarin to healthy elderly patients with $\mathrm{AF}^{25}$ in addition to prescriptions not being tailored to AF patients' risk factor profiles and risk scores. ${ }^{26-28}$ Use of anticoagulation might be increased by the availability of new oral agents, which postdated our study period, but there is currently little evidence of any increase in overall rates of anticoagulation in older age groups. $^{29} 30$

The low proportion of OXVASC patients with ischaemic stroke and known prior AF who were on premorbid oral anticoagulant is similar to that in a recent time trend study in France from 1985 to $2006 .^{31}$ All these non-anticoagulated OXVASC patients could still represent potentially preventable strokes even though a substantial proportion of them have already received other preventative medication(s) to address various risk factors before stroke onset. In addition, the numbers of potentially preventable embolic events outnumbered warfarin-related intracerebral haemorrhages by about 15 -fold at all ages and 50 -fold at age $\geq 80$ years. This finding indirectly supports observations from large cohort studies that the net clinical benefit favoured anticoagulation for almost all patients with $\mathrm{AF}$ at the population level except for those with very low embolic risk. ${ }^{32} 33$

The high proportion (31\%) of ischaemic stroke associated with AF in our study is consistent with other recent populationbased studies despite differences in definition of AF-related stroke (see online supplementary figure S2). ${ }^{34-36}$ Our results also show that major fatal/disabling ischaemic strokes predominate among elderly patients with AF-related cerebral events (figure 2) and in addition, confirm findings of earlier studies regarding the severity of AF-related strokes and related consequences of greater disability, increased likelihood of subsequent institutionalisation and higher mortality rate. ${ }^{34} 37$

Our study has several limitations. First, our findings cannot necessarily be generalised to other populations or healthcare systems. For example, rates of prior anticoagulation in patients with incident ischaemic stroke in OXVASC are somewhat lower than those in other recent stroke incidence studies (see online supplementary figure S2). However, under-use of anticoagulants is widely documented in all countries in which it has been studied, population ageing is widespread and other studies show that a high proportion of AF-related strokes occur at ages over 80 years. $^{31}$ Second, about a quarter of our patients aged $\geq 80$ with known prior AF had paroxysmal AF. However, the anticoagulation rate was low for both paroxysmal and permanent AF. Third, the lack of a documented reason in primary care or hospital records for patients with known prior AF for not being on warfarin might reflect poor documentation rather than undertreatment. However, the small number of patients who had been on warfarin previously but had discontinued its use was consistent with under-anticoagulation, as were the relatively low HAS-BLED scores in the majority of untreated patients, and our findings are consistent with previous studies. Fourth, although our retrospective calculation of the embolic and bleeding risk scores might have introduced some inaccuracies, information obtained from patients was cross-referenced with both hospital and primary care records. Fifth, not all vascular events in patients with $\mathrm{AF}$ would have been prevented by prior anticoagulation. However, warfarin reduces the rate of ischaemic stroke and PVE in primary prevention in AF by about 70\% compared with placebo, ${ }^{67}$ and so most of the events in untreated patients would have been preventable. In keeping with this conclusion, we found an alternative aetiology for stroke in only a small proportion of cases (see online supplementary table S7). Finally, evidence often takes several years to change clinical practice and even then, the impact of any changes on risk of vascular events would be further delayed. Moreover, we did not have individual patient data on anticoagulation rates in our underlying study population without vascular events. However, the rate of AF-related vascular events was higher in 2010-2012 than in 2007-2009.

In conclusion, a third of all fatal or disabling ischaemic strokes in people aged $\geq 80$ years in Oxfordshire occur in nonanticoagulated patients with known prior AF and there has been no reduction in this rate since introduction of the QOF and publication of the BAFTA trial. Improved prevention in older people with AF should be a major public health priority.

Acknowledgements The authors are grateful to all the staff in the general practices that collaborated in OXVASC: Abingdon Surgery, Stert St, Abingdon; Malthouse Surgery, Abingdon; Marcham Road Family Health Centre, Abingdon; The Health Centre, Berinsfield; Key Medical Practice, Kidlington; 19 Beaumont Street Surgery, Oxford; East Oxford Health Centre, Oxford; Church Street Practice, Wantage. They also acknowledge the use of the facilities of the Acute Vascular Imaging Centre, Oxford.

Contributors GSCY collected and analysed the data, and wrote the paper. DPJH LL and NLMP collected and analysed the data. ZM performed the data analysis. PMR designed the study and wrote the paper.

Funding The Oxford Vascular Study is funded by the Wellcome Trust, Wolfson Foundation, British Heart Foundation, Dunhill Medical Trust, UK Stroke Association National Institute for Health Research (NIHR) Oxford Biomedical Research Centre. PMR has a Wellcome Trust Senior Investigator Award and an NIHR Senior Investigator Award.

Competing interests None declared.

Patient consent Obtained.

Ethics approval The Oxford Vascular Study has been approved by our local research ethics committee.

Provenance and peer review Not commissioned; externally peer reviewed.

Open Access This is an Open Access article distributed in accordance with the terms of the Creative Commons Attribution (CC BY 4.0) license, which permits others to distribute, remix, adapt and build upon this work, for commercial use, provided the original work is properly cited. See: http://creativecommons.org/ licenses/by/4.0/

\section{REFERENCES}

1 Cowan C, Healicon R, Robson I, et al. The use of anticoagulants in the management of atrial fibrillation among general practices in England. Heart 2013;99:1166-72

2 Ball J, Carrington MJ, McMurray JJ, et al. Atrial fibrillation: profile and burden of an evolving epidemic in the 21st century. Int J Cardiol 2013;167:1807-24.

3 Heart and Stroke Improvement Commissioning for Stroke Prevention in Primary Care —The Role of Atrial Fibrillation. http://wwwnhsiqnhsuk/media/2335814/af_ commissioning_guidepdf (accessed 10 Apr 2014).

4 Luengo-Fernandez R, Yiin GS, Gray AM, et al. Population-based study of acute- and long-term care costs after stroke in patients with AF. Int J Stroke 2013;8:308-14. 
5 Menke J, Luthje L, Kastrup A, et al. Thromboembolism in atrial fibrillation. Am J Cardiol 2010;105:502-10.

6 Aguilar MI, Hart R, Pearce LA. Oral anticoagulants versus antiplatelet therapy for preventing stroke in patients with non-valvular atrial fibrillation and no history of stroke or transient ischemic attacks. Cochrane Database Syst Rev 2007;(3): CD006186.

7 Hart RG, Pearce LA, Aguilar MI. Meta-analysis: antithrombotic therapy to prevent stroke in patients who have nonvalvular atrial fibrillation. Ann Intern Med 2007; 146:857-67.

8 O'Donnell M, Oczkowski W, Fang J, et al. Preadmission antithrombotic treatment and stroke severity in patients with atrial fibrillation and acute ischaemic stroke: an observational study. Lancet Neurol 2006;5:749-54.

9 Connolly S, Pogue J, Hart R, et al. Clopidogrel plus aspirin versus oral anticoagulation for atrial fibrillation in the Atrial fibrillation Clopidogrel Trial with Irbesartan for prevention of Vascular Events (ACTIVE W): a randomised controlled trial. Lancet 2006;367:1903-12.

10 Ruff CT, Giugliano RP, Braunwald E, et al. Comparison of the efficacy and safety of new oral anticoagulants with warfarin in patients with atrial fibrillation: a meta-analysis of randomised trials. Lancet 2014;383:955-62.

11 Ogilvie IM, Newton N, Welner SA, et al. Underuse of oral anticoagulants in atrial fibrillation: a systematic review. Am J Med 2010;123:638-45 e4.

12 Gladstone DJ, Bui E, Fang J, et al. Potentially preventable strokes in high-risk patients with atrial fibrillation who are not adequately anticoagulated. Stroke 2009:40:235-40

13 Lakshminarayan K, Solid CA, Collins AJ, et al. Atrial fibrillation and stroke in the general medicare population: a 10-year perspective (1992 to 2002). Stroke 2006;37:1969-74.

14 Yiin GS, Howard DP, Paul NL, et al. Age-specific incidence, outcome, cost and projected future burden of atrial fibrillation-related embolic vascular events: a population-based study. Circulation 2014;130:1236-44.

15 Mant J, Hobbs FD, Fletcher $\mathrm{K}$, et al. Warfarin versus aspirin for stroke prevention in an elderly community population with atrial fibrillation (the Birmingham Atrial Fibrillation Treatment of the Aged Study, BAFTA): a randomised controlled trial. Lancet 2007;370:493-503.

16 Rothwell PM, Coull AJ, Giles MF, et al. Change in stroke incidence, mortality, case-fatality, severity, and risk factors in Oxfordshire, UK from 1981 to 2004 (Oxford Vascular Study). Lancet 2004;363:1925-33.

17 Coull AJ, Silver LE, Bull LM, et al. Direct assessment of completeness of ascertainment in a stroke incidence study. Stroke 2004;35:2041-5.

18 Sandercock P, Bamford J, Dennis $M$, et al. Atrial fibrillation and stroke: prevalence in different types of stroke and influence on early and long term prognosis (Oxfordshire community stroke project). BMJ 1992;305:1460-5.

19 Gage BF, Waterman AD, Shannon W, et al. Validation of clinical classification schemes for predicting stroke: results from the National Registry of Atrial Fibrillation. JAMA 2001;285:2864-70.

20 Lip GY, Nieuwlaat R, Pisters R, et al. Refining clinical risk stratification for predicting stroke and thromboembolism in atrial fibrillation using a novel risk factor-based approach: the Euro Heart Survey on atrial fibrillation. Chest 2010;137:263-72.
21 Pisters $R$, Lane DA, Nieuwlaat $R$, et al. A novel user-friendly score (HAS-BLED) to assess 1-year risk of major bleeding in patients with atrial fibrillation: the Euro Heart Survey. Chest 2010;138:1093-100.

22 Adams HP Jr, Bendixen BH, Kappelle LJ, et al. Classification of subtype of acute ischemic stroke. Definitions for use in a multicenter clinical trial. TOAST. Trial of Org 10172 in Acute Stroke Treatment. Stroke 1993:24:35-41.

23 Atrial fibrillation: the management of atrial fibrillation. http://guidanceniceorguk/ CG180; June 2014 (accessed 19 Jun 2014).

24 van Walraven C, Hart RG, Connolly $S$, et al. Effect of age on stroke prevention therapy in patients with atrial fibrillation: the Atrial Fibrillation Investigators. Stroke 2009:40:1410-16.

25 Pugh D, Pugh J, Mead GE. Attitudes of physicians regarding anticoagulation for atrial fibrillation: a systematic review. Age Ageing 2011;40:675-83.

26 Holt TA, Hunter TD, Gunnarsson C, et al. Risk of stroke and oral anticoagulant use in atrial fibrillation: a cross-sectional survey. Br J Gen Pract 2012;62: e710-17

27 Zimetbaum PJ, Thosani A, Yu HT, et al. Are atrial fibrillation patients receiving warfarin in accordance with stroke risk? Am J Med 2010;123:446-53.

28 Nieuwlaat R, Capucci A, Lip GY, et al. Antithrombotic treatment in real-life atrial fibrillation patients: a report from the Euro Heart Survey on Atrial Fibrillation. Eur Heart J 2006;27:3018-26

29 Larsen TB, Rasmussen LH, Skjoth F, et al. Efficacy and safety of dabigatran etexilate and warfarin in "real-world" patients with atrial fibrillation: a prospective nationwide cohort study. J Am Coll Cardiol 2013;61:2264-73.

30 Kirley K, Qato DM, Kornfield R, et al. National trends in oral anticoagulant use in the United States, 2007 to 2011. Circ Cardiovasc Qual Outcomes 2012;5:615-21

31 Bejot $Y$, Ben Salem D, Osseby GV, et al. Epidemiology of ischemic stroke from atrial fibrillation in Dijon, France, from 1985 to 2006. Neurology 2009;72:346-53.

32 Olesen JB, Lip GY, Lindhardsen J, et al. Risks of thromboembolism and bleeding with thromboprophylaxis in patients with atrial fibrillation: a net clinical benefit analysis using a 'real world' nationwide cohort study. Thromb Haemost 2011;106:739-49.

33 Friberg L, Rosenqvist M, Lip GY. Net clinical benefit of warfarin in patients with atrial fibrillation: a report from the Swedish atrial fibrillation cohort study. Circulation 2012;125:2298-307.

34 Hannon N, Sheehan O, Kelly L, et al. Stroke associated with atrial fibrillationincidence and early outcomes in the north Dublin population stroke study. Cerebrovasc Dis 2010;29:43-9.

35 Leyden JM, Kleinig TJ, Newbury J, et al. Adelaide stroke incidence study: declining stroke rates but many preventable cardioembolic strokes. Stroke 2013;44: 1226-31.

36 Palm F, Kleemann T, Dos Santos M, et al. Stroke due to atrial fibrillation in a population-based stroke registry (Ludwigshafen Stroke Study) CHADS(2), CHA(2) DS (2) -VASC score, underuse of oral anticoagulation, and implications for preventive measures. Eur J Neurol 2013;20:117-23.

37 Lin HJ, Wolf PA, Kelly-Hayes M, et al. Stroke severity in atrial fibrillation. The Framingham Study. Stroke 1996:27:1760-4. 